\title{
Effects of long chain fatty acids on solute absorption: perfusion studies in the human jejunum ${ }^{1}$
}

\author{
H. V. AMMON, ${ }^{2}$ P. J. THOMAS, AND S. F. PHILliPS ${ }^{2}$ \\ From the Gastroenterology Unit, Mayo Clinic and Mayo Foundation, Rochester, Minnesota; the \\ Gastroenterology Section, Medical Service, Veterans Administration Center, Wood (Milwaukee), \\ Wisconsin; and the Department of Medicine, The Medical College of Wisconsin, Milwaukee, Wisconsin, \\ USA
}

SUMMARY Perfusion studies were performed in healthy volunteers to test the hypothesis that net fluid secretion induced by fatty acids is accompanied by parallel reduction in solute transport. Ricinoleic acid provoked a marked net secretion of fluid and concomitantly inhibited the absorption of all solutes tested; these included glucose, xylose, L-leucine, L-lysine, folic acid, and 2-mono-olein. Oleic acid also reduced net fluid and solute transport, but was less potent in reducing solute absorption than was ricinoleic acid. When fluid secretion was induced osmotically with mannitol, glucose and xylose absorption was not affected. The mechanism for this generalised effect of fatty acids on solute absorption is uncertain, possibly nonspecific, and might be related to mucosal damage and altered mucosal permeability induced by these agents.

Perfusion of the bowel with dihydroxy bile acids results in net water secretion (Sladen and Harries, 1972; Wingate et al., 1973b; Russell et al., 1973; Krag and Phillips, 1974). When water secretion is thus induced, electrolytes are also secreted (Wingate et al., 1973a), and absorption of organic solutes is reduced (Sladen and Harries, 1972; Wingate et al., 1973b; Krag and Phillips, 1974). Long chain fatty acids also modify intestinal water transport, and when ileal fluid absorption is inhibited by ricinoleic acid, absorption of taurocholate and glucose is reduced concomitantly (Ammon and Phillips, 1974). Other intestinal secretogogues have variable effects on glucose absorption. Matuchansky and Bernier (1973) found reduced glucose absorption when jejunal secretion is induced by prostaglandin $E_{1}$, but glucose

\footnotetext{
${ }^{1}$ Presented in part at the Central Society for Clinical Research, Chicago, Illinois, 2 November 1974, and at the Midwest Section of the American Federation for Clinical Research, Chicago, Illinois, 8 November 1975. Published in part in abstract form: Clinical Research (1975) 22, 634, and (1975) 23, 480 .

${ }^{2}$ Addresses for reprint requests: Dr Helmut V. Ammon, Gastroenterology Section/111C, Veterans Administration Center, Wood, Wisconsin 53193, USA, or Dr S. F. Phillips, Gastroenterology Unit, Mayo Clinic, Rochester, Minnesota 55901, USA.
}

Received for publication 26 February 1977 absorption is unimpaired when fluid secretion is evoked by cholera toxin (Carpenter et al., 1968; Serebro et al., 1968).

In this paper we report the absorption of several organic solutes (glucose, xylose, leucine, lycine, folic acid, mono-olein) from the human jejunum, under control conditions of fluid absorption, and during fluid secretion induced by fatty acids, bile acids, and mannitol.

\section{Methods}

\section{PREPARATION OF PERFUSATES}

Chemicals used were identical with those described in a previous paper (Ammon et al., 1974) with the following additions: (1) folic acid (pteroylglutamic acid) was purchased from Schwartz-Mann, Orange, New Jersey (99.5\% pure); (2) folic acid $3^{\prime}, 5^{\prime}, 9-{ }^{3} \mathrm{H}$ was purchased from Amersham-Searle, Arlington Heights, Illinois, and was $97 \%$ pure by thin-layer chromatography; (3) taurodeoxycholic acid was synthesised as described previously (Hofmann, 1963), and (4) the unconjugated precursor, deoxycholic acid; was obtained from ICN Pharmaceuticals, Cleveland, Ohio. Detailed compositions of test solutions are given later in the Experimental Design and Results section. 
PERFUSION TECHNIQUE

The perfusion technique described previously (Ammon et al., 1974) uses a four-lumen tube. A balloon was positioned to occlude the bowel at the ligament of Treitz and the $25 \mathrm{~cm}$ test segment was distal to the balloon. Perfusates were delivered at a constant rate of $10 \mathrm{ml} / \mathrm{min}$, at $37^{\circ} \mathrm{C}$, and effluent was obtained by siphonage. Each solution was perfused for 70-90 minutes, the first 30 minutes were used for equilibration. Samples were collected for consecutive six 10-minute or eight five-minute intervals. Steady state conditions were confirmed by stable concentrations of polyethylene glycol (PEG) during these sequential sampling periods and all results refer to observations during the steady-state. Studies were performed in healthy volunteers according to protocols approved by the Human Studies Committees of Mayo Clinic and the Wood Veterans Administration Center. Nineteen subjects were studied on 23 separate perfusion days.

\section{ANALYTICAL METHODS}

PEG was measured by determination of ${ }^{14} \mathrm{C} \mathrm{PEG}$ or turbidimetrically (Wingate et al., 1972) when other ${ }^{14} \mathrm{C}$-labelled compounds were present. Glucose was determined by the glucose oxidase method (Boehringer-Mannheim Corporation, New York) and xylose by the o-toluidine method (Goodwin, 1970). L-leucine and L-lysine were measured with a Beckman amino acid analyser. Folic acid and 2mono-olein were determined by the recovery of ${ }^{3} \mathbf{H}$ or ${ }^{14} \mathrm{C}$ from the perfusates, respectively. For isotope determinations $1 \mathrm{ml}$ of the perfusate or effluent was mixed with $15 \mathrm{ml}$ of a scintillation cocktail consisting of toluene and emulsifier (Ready Solv VI, Beckman Instruments, Inc., Fullerton, California) and counted by liquid scintillation spectrometry. Quench correction was made by external standardisation. Samples containing dual isotopes were counted in two channels. CPMs were converted into DPMs for each isotope with a computer programme which corrected for quenching and spillover of ${ }^{14} \mathrm{C}$ into the tritium channel (Okita et al., 1957). Spillover of tritium into the ${ }^{14} \mathrm{C}$ channel was less than $1 \%$.

CALCUlations AND STATISTICAL ANALYSIS Absorption of water and solutes over the $25 \mathrm{~cm}$ test segment was calculated relative to a change in the concentration of PEG. Water movement is expressed in $\mathrm{ml} / \mathrm{min}$ as the mean of six 10-minute or eight fiveminute collection periods. Solute absorption is expressed in percent absorption, thereby allowing comparison of relative absorption rates between different solutes that were present in varying absolute amounts. Net movement of water and net absorption of solutes were evaluated statistically by paired and unpaired $t$ tests.

\section{Experimental design and results}

EXPERIMENT NO. 1

Absorption of glucose and xylose in presence of varying concentrations of oleic and ricinoleic acids Glucose and xylose absorption was measured in experiments (Ammon et al., 1974) designed primarily to test the effects of oleic and ricinoleic acids on jejunal water transport at concentrations of $0 \cdot 5,2 \cdot 0$, and $5.0 \mathrm{mM}$. Four volunteers were studied on two occasions, one with each fatty acid. A Latin square design (Wingate et al., 1973b) was used to eliminate the effect of perfusion sequence. All solutions were isotonic $(280 \mathrm{mOsm} / 1 ; \mathrm{pH} 7 \cdot 5)$ and contained $5 \mathrm{mM}$ taurocholate for micellar solubilisation of the fatty acids and PEG $5 \mathrm{~g} / \mathrm{l}$ as a nonabsorbable marker. The control solution contained $\mathrm{Na} 120, \mathrm{~K} \mathrm{10}, \mathrm{Cl} 100$, and $\mathrm{HCO}_{3} 30 \mathrm{mEq} / \mathrm{l}$; glucose $11.2 \mathrm{mM}$; xylose $11.2 \mathrm{mM}$, and ${ }^{14} \mathrm{C}$ PEG $5 \mu \mathrm{Ci} / 1$. Fatty acid solutions contained ricinoleic or oleic acid in the concentrations stated above.

The results shown in Table 1 indicate that ricinoleic acid inhibited the absorption of both sugars starting at $2 \mathrm{mM}(\mathrm{P}<0.05)$, while oleic acid up to 5 $\mathrm{mM}$ had no significant effect on sugar absorption. The table also shows, for purposes of comparison, the previously reported data on water movement (Ammon et al., 1974), which indicate that ricinoleic acid was more potent in reducing water absorption.

EXPERIMENT NO. 2

Glucose and xylose absorption during secretion induced by fatty acids, bile acids, and mannitol We attempted to induce net fluid secretion of approximately equal magnitude by perfusing oleic acid, ricinoleic acid, taurodeoxycholate, or mannitol. We wished to compare the effects of the two fatty acids and a bile acid on sugar transport (independent of the degree of fluid secretion), with the effects of net flow into the lumen produced by a different (osmotic) mechanism.

In five volunteers, five solutions were perfused in random sequence. The control solution (A) contained, in $\mathrm{mM}$ or $\mathrm{mEq} / \mathrm{l}: \mathrm{NaCl} 115, \mathrm{KCl} 5, \mathrm{NaHCO}_{3}$ 10 , glucose $11 \cdot 2$, xylose $11 \cdot 2$, PEG $5 \mathrm{~g} / \mathrm{l}$. Test solutions differed by the following additions: solutions $B$ and $C$ contained, with appropriate adjustment of electrolyte concentration, taurocholate $(10 \mathrm{mM})$ and ricinoleic acid or oleic acid $(10 \mathrm{mM})$, respectively. Solution D contained $7 \mathrm{mM}$ taurodeoxycholate. All these solutions were adjusted to $\mathrm{pH} 7.5$ and an 
Table 1 Effect of oleic acid $(O A)$ and ricinoleic acid $(R A)$ on absorption of glucose $(11 \cdot 2 \mathrm{mM})$ and xylose $(11.2 \mathrm{mM})($ mean $\pm S E M$ of four subjects; each subject studied separately with $O A$ and $R A$; perfusion rate $10 \mathrm{ml} / \mathrm{min}$ )

\begin{tabular}{|c|c|c|c|}
\hline \multirow[t]{2}{*}{ Fatty acid perfused $(m M)^{*}$} & \multicolumn{3}{|c|}{ Absorption per $25 \mathrm{~cm}$ human jejunum } \\
\hline & Water $(\mathrm{ml} / \mathrm{min}) \dagger$ & Glucose (\%) & Xylose $(\%)$ \\
\hline $\begin{array}{l}\text { Control } \\
\text { RA } 0 \cdot 5 \\
\text { RA } 2 \\
\text { RA } 5\end{array}$ & $\begin{array}{r}1.7 \pm 0.5 \\
0.5 \pm 0.2 \\
-0.6 \pm 0.4 \ddagger \\
-1.6 \pm 0.69\end{array}$ & $\begin{array}{l}61 \cdot 2 \pm 16 \cdot 7 \\
44 \cdot 5 \pm 11 \cdot 3 \\
28 \cdot 5 \pm 10 \cdot 0 \pi \\
24 \cdot 1 \pm 5 \cdot 2 \pi\end{array}$ & $\begin{array}{r}27 \cdot 7 \pm 7 \cdot 1 \\
18.5 \pm 5 \cdot 6 \ddagger \\
7 \cdot 1 \pm 2 \cdot 6 \rrbracket \\
6.0 \pm 2.4 \S\end{array}$ \\
\hline
\end{tabular}

*All solutions contained taurocholate $5 \mathrm{mM}$.

$\dagger$ Minus signs indicate net secretion.

Control vs test: $\ddagger \mathrm{P}<0.05 ;$ ๆP $<0.025 ; \S P<0.01$.

Table 2 Effect of fatty acids, taurodeoxycholate, and mannitol on absorption of glucose $(11 \cdot 2 \mathrm{mM})$ and $x y$ lose $(11 \cdot 2 \mathrm{mM})($ mean $\pm S E M$ from studies in random sequence in five subjects; perfusion rate $10 \mathrm{ml} / \mathrm{min})$

\begin{tabular}{|c|c|c|c|c|c|}
\hline \multirow[t]{2}{*}{ Test circumstances } & \multicolumn{3}{|c|}{ Absorption per $25 \mathrm{~cm}$ human jejunum } & \multicolumn{2}{|c|}{ Mean segment concentration } \\
\hline & Water $(\text { ml/min })^{*}$ & Glucose $(\%)$ & Xylose (\%) & Glucose $(m M)$ & Xylose $(m M)$ \\
\hline Control & $1.4 \pm 0.6$ & $80 \cdot 7 \pm 6 \cdot 5$ & $23 \cdot 4 \pm 6 \cdot 2$ & $6.6 \pm 0.4$ & $10.9 \pm 0.4$ \\
\hline $\begin{array}{l}\text { Taurocholic acid } 10 \mathrm{mM} \\
\text { Ricinoleic acid } 10 \mathrm{mM}\end{array}$ & $-2 \cdot 1 \pm 0.4 \ddagger$ & $18 \cdot 4 \pm 2 \cdot 79$ & $6 \cdot 3 \pm 2.9 \dagger$ & $9 \cdot 1 \pm 0 \cdot 3_{+}^{+}$ & $9.9 \pm 0.2$ \\
\hline $\begin{array}{l}\text { Taurocholic acid } 10 \mathrm{mM} \\
\text { Oleic acid } 10 \mathrm{mM}\end{array}$ & $-2.6 \pm 0.8 \dagger$ & $35 \cdot 8 \pm 9 \cdot 1+\S$ & $10 \cdot 6 \pm 1.9 \S$ & $8.5 \pm 0.5 \dagger$ & $9.6 \pm 0.3$ \\
\hline Taurodeoxycholic acid $7 \mathrm{mM}$ & $-1.3 \pm 0.3 \dagger$ & $49 \cdot 0 \pm 7 \cdot 8 \dagger$ & $13 \cdot 0 \pm 1 \cdot 3$ & $7 \cdot 9 \pm 0 \cdot 4 \ddagger$ & $9.9 \pm 0.2$ \\
\hline $\begin{array}{l}\text { Control + mannitol } \\
(450 \mathrm{mOsm} / \mathrm{l})\end{array}$ & $-3.5 \pm 0.8 \ddagger$ & $74 \cdot 1 \pm 6 \cdot 4$ & $15 \cdot 0 \pm 1 \cdot 5$ & $6.5 \pm 0.3$ & $9 \cdot 3 \pm 0 \cdot 4 \ddagger$ \\
\hline
\end{tabular}

* Minus signs indicate net secretion.

Test vs control: $\dagger_{P}<0.025 ; \ddagger_{P}<0.01 ; \prod_{P}<0.0025$.

Oleic acid vs ricinoleic acid: $\S P<0.05$.

osmolality of $280 \mathrm{mOsm} / \mathrm{l}$. Solution $\mathrm{E}$ had the same composition as $\mathrm{A}$, and, in addition, contained mannitol to a final osmolality of $450 \mathrm{mOsm} / \mathrm{l}$.

The results (Table 2) show that at $10 \mathrm{mM}$ oleic acid induced equal rates of fluid secretion as did ricinoleic acid (Ammon et al., 1974). When fluid secretion was induced by the fatty acids or taurodeoxycholic acid, glucose absorption was reduced $(\mathrm{P}<0.01)$. Ricinoleic acid was a more potent inhibitor of glucose absorption $(P<0.05)$ (Table 2), than was oleic acid, despite comparable rates of fluid secretion. A similar reduction in xylose absorption was noted, although the changes in the absorption of xylose were less than those of glucose. In contrast, when fluid secretion of even greater magnitude was induced by mannitol, glucose absorption was unaffected.

Mean concentrations of glucose in the test segment were greater in the presence of fatty acids and taurodeoxycholic acid than in the control period (P $<0.025$ ) (Table 2); whereas, in the presence of man- nitol, glucose concentration was unchanged. Mean xylose concentration was significantly less than control only in the presence of mannitol-induced fluid secretion $(P<0.01)$.

EXPERIMENT NO. 3

\section{Effect of $10 \mathrm{mM}$ ricinoleic acid on 'uphill'}

glucose absorption

During perfusion with $10 \mathrm{mM}$ ricinoleic acid the concentrations of glucose in effluents from the test segments were above the normal fasting blood glucose concentration (5-6 mM). We therefore compared absorption of glucose, infused at a concentration of $2 \mathrm{mM}$ in two volunteers, in isotonic electrolyte solutions with or without $10 \mathrm{mM}$ taurocholate and $10 \mathrm{mM}$ ricinoleic acid. Water movement changed from 2.5 and $0.1 \mathrm{ml} / \mathrm{min}$ (absorption) to -3.4 and $-2.6 \mathrm{ml} / \mathrm{min}$ (secretion), respectively. Glucose absorption decreased from 86.7 and $83.9 \%$ to 15.5 and $39.7 \%$ in the presence of fatty acid. 
EXPERIMENT NO. 4

Effects of ricinoleic acid on absorption of L-leucine and L-lysine

In another set of experiments, we measured the effects of ricinoleic acid on absorption of two amino acids with different active transport sites (Larsen et al., 1964). Each of four subjects received the following solutions in random sequence: (1) an electrolyte solution containing $5 \mathrm{mM}$ taurocholate; (2) an electrolyte solution containing $5 \mathrm{mM}$ taurocholate and $2.5 \mathrm{mM}$ ricinoleic acid; (3) an electrolyte solution containing $5 \mathrm{mM}$ taurochenodeoxycholate; and (4) an electrolyte solution containing $5 \mathrm{mM}$ taurochenodeoxycholate and $2.5 \mathrm{mM}$ ricinoleic acid. The electrolyte solution contained $\mathrm{Na} 115, \mathrm{~K} 10, \mathrm{Cl} 100$, and $\mathrm{HCO}_{3} 25 \mathrm{mEq} / \mathrm{l}$; PEG $5 \mathrm{~g} / 1$ with ${ }^{14} \mathrm{C}$ PEG $5 \mu \mathrm{Ci} / \mathrm{l}$. It also contained D-xylose $11.2 \mathrm{mM}$, L-leucine $10 \mathrm{mM}$, L-lysine $10 \mathrm{mM}$; pH was 7.5 and osmolality 280 $\mathrm{mOsm} / 1$.

As shown in Table 3, water and xylose absorption under control conditions with the nonsecretory bile acid, taurocholate, were comparable with earlier results. Ricinoleic acid at $2.5 \mathrm{mM}$ significantly reduced the absorption of leucine and lysine $(P<$ 0.05 ). The reduction of amino acid absorption seen with taurochenodeoxycholate did not reach statistical significance.
EXPERIMENT NO. 5

Effects of fatty acids on absorption of folic acid In some studies of experiments nos. 1 and 4 , trace amounts of folic acid were included in test solutions $\left(0.2 \mu \mathrm{M}\right.$ with $20 \mu \mathrm{Ci} / 13^{\prime}, 5^{\prime}, 9-{ }^{3} \mathrm{H}$-labelled). Test solutions were $5 \mathrm{mM}$ oleic acid (two studies), $5 \mathrm{mM}$ ricinoleic acid (two studies), and $2.5 \mathrm{mM}$ ricinoleic acid (three studies). Subjects were given $1 \mathrm{mg}$ folic acid intravenously 30 minutes before the experiment. In every instance, the absorption of folic acid was reduced markedly when fatty acid was present in the perfusate (Table 4). Mean absorption of folic acid during all control experiments was (mean \pm SE) 27.4 $\pm 5.2 \%$, and this decreased to $9.6 \pm 3.7 \%$ in the presence of fatty acids $(\mathrm{P}<0.05)$ (paired $t$ test).

EXPERIMENT NO. 6

Effects of fatty acids on absorption of 2-mono-olein

To study effects on the absorption of a lipid, the following four solutions were perfused in random sequence in four subjects: (1) control solution; (2) control solution with $2.5 \mathrm{mM} 2$-mono-olein, (3) control solution with $2.5 \mathrm{mM} 2$-mono-olein and $5 \mathrm{mM}$ oleic acid; and (4) control solution with $2.5 \mathrm{mM} 2$ mono-olein and $5 \mathrm{mM}$ ricinoleic acid. The control solution contained $\mathrm{Na} 110, \mathrm{~K} 10, \mathrm{Cl} 90$, and $\mathrm{HCO}_{3}$

Table 3 Effect of ricinoleic acid $(R A)$ on absorption of L-leucine $(10 \mathrm{mM})$, L-lysine $(10 \mathrm{mM})$, and $D$-xylose $(11.2 \mathrm{mM})$ (mean $\pm S E M$ from studies in random sequence in four subjects; perfusion rate $10 \mathrm{ml} / \mathrm{min})$

\begin{tabular}{|c|c|c|c|c|}
\hline \multirow[t]{2}{*}{ Test circumstances } & \multicolumn{4}{|c|}{ Absorption per $25 \mathrm{~cm}$ human jejunum } \\
\hline & Water $(\mathrm{ml} / \mathrm{min})^{*}$ & Leucine $(\%)$ & Lysine $(\%)$ & Xylose (\%) \\
\hline $\begin{array}{l}\text { Taurocholate (TC) }(5 \mathrm{mM}) \\
\text { TC }(5 \mathrm{mM})+\text { RA }(2.5 \mathrm{mM}) \\
\text { Taurochenodeoxycholate }(\text { TCDC })(5 \mathrm{mM}) \\
\text { TCDC }(5 \mathrm{mM})+\text { RA }(2.5 \mathrm{mM})\end{array}$ & $\begin{aligned} 1.2 & \pm 0.5 \\
-0.5 & \pm 0.8 \ddagger \\
0.1 & \pm 0.6 \ddagger \\
-0.3 \pm 0.5 \dagger & \pm\end{aligned}$ & $\begin{array}{l}52 \cdot 2 \pm 14 \cdot 9 \\
39 \cdot 8 \pm 16 \cdot 2 \dagger \\
47 \cdot 3 \pm 13 \cdot 4 \\
38 \cdot 6 \pm 12 \cdot 2 \ddagger\end{array}$ & $\begin{array}{l}34 \cdot 7 \pm 12 \cdot 2 \\
26 \cdot 3 \pm 10 \cdot 4 \dagger \\
32 \cdot 9 \pm 7 \cdot 5 \\
24 \cdot 7 \pm 9 \cdot 1\end{array}$ & $\begin{array}{l}21 \cdot 5 \pm 8 \cdot 3 \\
11 \cdot 2 \pm 4 \cdot 7 \dagger \\
17 \cdot 8 \pm 6 \cdot 1 \\
13 \cdot 8 \pm \mathbf{4 \cdot 3}\end{array}$ \\
\hline
\end{tabular}

* Minus signs indicate net secretion.

Test vs TC $(5 \mathrm{mM}): \nmid \mathrm{P}<0.05 ; \ddagger \mathrm{P}<0.025$.

Table 4 Effect of oleic acid $(O A)$ and ricinoleic acid $(R A)$ on absorption of folic acid $(0.2 \mu M)$

\begin{tabular}{|c|c|c|c|c|}
\hline \multirow[t]{3}{*}{ Fatty acid perfused ( $m M$ ) } & \multicolumn{4}{|c|}{ Absorption per $25 \mathrm{~cm}$ human jejunum* } \\
\hline & \multicolumn{2}{|l|}{ Control $\dagger$} & \multicolumn{2}{|l|}{ Test $\dagger$} \\
\hline & Water (ml/min) & Folate (\%) & Water $(\operatorname{ml} / \min ) \ddagger$ & Folate $(\%)$ \\
\hline OA 5 & $\begin{array}{l}0.7 \\
2.2\end{array}$ & $\begin{array}{l}19 \\
38\end{array}$ & $\begin{array}{r}-0.3 \\
0.8\end{array}$ & $\begin{array}{l}13 \cdot 3 \\
27 \cdot 5\end{array}$ \\
\hline RA 5 & $\begin{array}{l}2.4 \\
0.6\end{array}$ & $\begin{array}{r}45 \cdot 6 \\
9 \cdot 5\end{array}$ & $\begin{array}{l}-3.2 \\
-0.6\end{array}$ & $\begin{array}{l}0.4 \\
0.1\end{array}$ \\
\hline RA $2 \cdot 5$ & $\begin{array}{l}1.9 \\
0.5 \\
0.4\end{array}$ & $\begin{array}{l}41 \\
18 \cdot 7 \\
20 \cdot 2\end{array}$ & $\begin{array}{l}-1.5 \\
-0.7 \\
-1.5\end{array}$ & $\begin{array}{r}11 \cdot 2 \\
2.6 \\
11 \cdot 8\end{array}$ \\
\hline
\end{tabular}

*Perfusion rate $10 \mathrm{ml} / \mathrm{min}$.

†All solutions contained taurocholate $5 \mathrm{mM}$.

$\ddagger$ Minus signs indicate net secretion. 
$20 \mathrm{mEq} / 1$, PEG $5 \mathrm{~g} / \mathrm{l}$, taurocholate $10 \mathrm{mM}$, glucose $11.2 \mathrm{mM}$, and xylose $11.2 \mathrm{mM}$. Appropriate test solutions contained ${ }^{14} \mathrm{C}$ 2-mono-olein $5 \mu \mathrm{Ci} / 1$ and ${ }^{3} \mathrm{H}$ ricinoleic acid or ${ }^{3} \mathrm{H}$ oleic acid $20 \mu \mathrm{Ci} / 1 ; \mathrm{pH}$ was 7.5 and osmolality $280 \mathrm{mOsm} / \mathrm{l}$. Labelled fatty acids were used in these experiments to simplify the measurement of fatty acid absorption in the presence of mono-olein.

When fluid secretion was induced by either fatty acid, the absorption of glucose, xylose and 2-monoolein was reduced (Table 5). Xylose absorption was significantly reduced in the presence of each fatty acid $(P<0.05)$. The changes in the absorption of glucose and mono-olein reached statistical significance only in the presence of ricinoleic acid $(P<$ 0.01).

EXPERIMENT NO. 7

Influence of added mono-olein and lecithin on solute absorption reduced by ricinoleic acid

Absorption rates of glucose $(11.2 \mathrm{mM})$ and xylose $(11.2 \mathrm{mM})$ were also measured in experiments designed to test the effects of 2-mono-olein and lecithin on fluid secretion induced by ricinoleic acid (Ammon et al., 1974). Each of four subjects was perfused in random sequence with (1) a control solution;
(2) the control solution with ricinoleic acid, $5 \mathrm{mM}$; (3) the control solution with ricinoleic acid, $5 \mathrm{mM}$ and 2-mono-olein, $2.5 \mathrm{mM}$; and (4) the control solution with $5 \mathrm{mM}$ ricinoleic acid, $2.5 \mathrm{mM} 2$-mono-olein, and $2.5 \mathrm{mM}$ lecithin. The composition of the control solution was similar to that described in experiment no. 6.

The addition of mono-olein or lecithin had no effect on the fluid secretion induced by ricinoleic acid nor on the associated reduction in glucose absorption. Xylose absorption was somewhat improved, however, the absorption rates were not significantly different from those during perfusion with ricinoleic acid alone (Table 6).

\section{Discussion}

The phenomenon documented here is that intraluminal fatty acids inhibit the absorption of a variety of organic solutes from the human jejunum. Substances whose absorption was reduced include: (1) two sugars, one that is actively and one that is passively transported except at very low luminal concentrations (Alvarado, 1966); (2) two amino acids with different transport systems; (3) folic acid, and (4) a lipid, 2-mono-olein. In earlier experiments from our laboratory, absorption of taurocholate and

Table 5 Effect of oleic acid $(O A)$ and ricinoleic acid $(R A)$ on absorption of 2-mono-olein (2.5 mM), glucose $(11.2 \mathrm{mM})$ and $x y$ lose $(11.2 \mathrm{mM})$ (mean \pm SEM from studies in random sequence in four subjects; perfusion rate $10 \mathrm{ml} / \mathrm{min})$

\begin{tabular}{|c|c|c|c|c|}
\hline \multirow[t]{2}{*}{ Test circumstances* } & \multicolumn{4}{|c|}{ Absorption per $25 \mathrm{~cm}$ human jejunum } \\
\hline & Water $(\mathrm{ml} / \mathrm{min}) \dagger$ & Mono-olein (\%) & Glucose $(\%)$ & Xylose $(\%)$ \\
\hline $\begin{array}{l}\text { Control } \\
\text { Mono-olein } 2.5 \mathrm{mM} \\
\text { Mono-olein 2.5 mM }+ \text { OA } 5 \mathrm{mM} \\
\text { Mono-olein 2.5 mM }+ \text { RA } 5 \mathrm{mM}\end{array}$ & $\begin{aligned} & 1.0 \pm 0.4 \\
& 0.8 \pm 0.1 \\
&-0.7 \pm 0.6 \pm \S \\
&-1.6 \pm 0.5 \Upsilon^{* *}\end{aligned}$ & $\begin{array}{l}5 \overline{51 \cdot 5} \pm 3.6 \\
37 \cdot 7 \pm 10 \cdot 2 \\
6.7 \pm 3.99\end{array}$ & $\begin{array}{l}66.8 \pm 9.8 \\
58.4 \pm 4.6 \\
52.7 \pm 11.2 \\
21.6 \pm 4.5 \eta^{* *}\end{array}$ & $\begin{aligned} 17 \cdot 3 & \pm 2 \cdot 3 \\
15.9 & \pm 1 \cdot 8 \\
7 \cdot 8 & \pm 4 \cdot 7 \S \\
5 \cdot 3 & \pm 0.89^{* *}\end{aligned}$ \\
\hline
\end{tabular}

*All solutions contained taurocholate $10 \mathrm{mM}$.

$\dagger$ Minus signs indicate net secretion.

Test vs mono-olein: $\ddagger \mathbf{P}<0.05 ; \eta_{\mathbf{P}}<0.01$.

Test vs control: §P $<0.05 ;{ }^{* *} P<0.01$.

Table 6 Effects of 2-mono-olein and lecithin on ricinoleic acid $(R A)$ induced changes in water transport and absorption of glucose $(11.2 \mathrm{mM}$ ) and xylose $(11 \cdot 2 \mathrm{mM})$ (mean $\pm S E M$ from studies in random sequence in four subjects; perfusion rate $10 \mathrm{ml} / \mathrm{min}$ )

\begin{tabular}{|c|c|c|c|}
\hline \multirow[t]{2}{*}{ Test circumstances* } & \multicolumn{3}{|c|}{ Absorption per $25 \mathrm{~cm}$ human jejunum } \\
\hline & Water $(\mathrm{ml} / \mathrm{min}) \dagger$ & Glucose $(\%)$ & Xylose (\%) \\
\hline $\begin{array}{l}\text { Control } \\
\text { RA } 5 \mathrm{mM} \\
\text { RA } 5 \mathrm{mM}+\text { mono-olein } 2.5 \mathrm{mM} \\
\text { RA } 5 \mathrm{mM}+\text { mono-olein } 2.5 \mathrm{mM}+\text { lecithin } 2.5 \mathrm{mM}\end{array}$ & $\begin{array}{r}1.3 \pm 0.05 \\
-1.7 \pm 0.5 \ddagger \\
-1.5 \pm 0.29 \S \\
-1.4 \pm 0.6 \ddagger \S\end{array}$ & 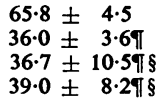 & $\begin{aligned} 21 \cdot 8 & \pm 1 \cdot 8 \\
8 \cdot 6 & \pm 2 \cdot 6 \ddagger \\
11 \cdot 7 & \pm 2 \cdot 9 \ddagger \S \\
13 \cdot 8 & \pm 5 \cdot 6 \S\end{aligned}$ \\
\hline
\end{tabular}

* All solutions contained taurocholate $10 \mathrm{mM}$.

†Minus signs indicate net secretion.

Test vs control: $¥ P<0.05 ;$ TP $<0.01$.

Test vs RA: §Not significant. 
glucose was inhibited when ricinoleic acid or oleic acid was perfused in the canine ileum (Ammon and Phillips, 1974). This conflicts with an earlier study in the dog ileum, in which glucose absorption was enhanced in the presence of oleic acid (Riddell and Jordan, 1966). However, in those experiments, glucose was administered in a hypertonic solution (168 $\mathrm{mM}$ glucose in Krebs-Ringer solution), and the present studies therefore are not strictly comparable. Several observations have shown reduced solute absorption when fluid secretion is stimulated by dihydroxy bile acids; those results are similar to the present findings. Thus, dihydroxy bile acids impair the absorption of glucose (Forth et al., 1966; Sladen and Harries, 1972; Wingate et al., 1973b; Krag and Phillips, 1974), amino acids (Hajjar et al., 1975; Burke et al., 1975), oleic acid (Wanitschke and Ammon, 1976), linoleic acid, cholesterol, and vitamin $D_{3}$ (Lenormand et al., 1975). Our test solutions contained taurocholate to allow micellar solubilisation of the fatty acids. However, the low concentration of taurocholate employed here was confirmed as being nonsecretory (Ammon et al., 1974), justifying its use in other test solutions.

At concentrations below $10 \mathrm{mM}$, ricinoleic acid was shown to be a more potent stimulus to water secretion than oleic acid (Ammon et al., 1974). In addition, ricinoleic acid reduced the absorption of solutes more than oleic acid when both fatty acids induced comparable rates of fluid secretion (Table 2). Although we wanted to compare the inhibitory influence of dihydroxy bile acids and fatty acids on solute absorption when rates of fluid secretion were similar, less water was secreted in the presence of dihydroxy bile acids and a strict comparison was not possible. Fluid secretion induced by hypertonic mannitol was not associated with changes in glucose absorption. This is in contrast with observations in the rat in which hypertonic solutions inhibited glucose absorption, and a net movement of glucose into the lumen and marked morphological changes were noted (Kameda et al., 1968). However, the same investigators failed to observe this effect in the human jejunum (Nasrallah et al., 1968).

The perfusion technique used in this study has been employed previously to determine the effects of dihydroxy bile acids (Wingate et al., 1973b), fatty acids (Ammon et al., 1974), and prostaglandins (Matuchansky and Bernier, 1973) on water and solute absorption in the human jejunum. However, in view of the sequential nature of our observations and the fact that dihydroxy bile acids (Dawson and Isselbacher, 1960; Teem and Phillips, 1972; Hajjar et al., 1975) and hydroxy fatty acids (Reynell and Spray, 1958; Cline et al., 1976; Gaginella and Phillips, 1976) produce mucosal damage in the small bowel, it is necessary to confirm the reversibility of fatty acid effects on water and solute transport observed in our system. The randomisation of perfusion sequence compensates for possible delayed effects and ensures that the observations are qualitatively correct. Previous reports document that the effect of dihydroxy bile acids (Wingate et al., 1973b) and $10 \mathrm{mM}$ fatty acids (Ammon et al., 1974) on water transport in the human jejunum revert back to control values within a 30-minute equilibration period. However, in the canine ileum, we observed a prolonged effect of ricinoleic acid on water transport, lasting more than one hour (Ammon and Phillips, 1974). We therefore checked the completeness of recovery by comparing absorptions of water, xylose, and glucose in two groups of control perfusions. One group $(n=7)$ came from experiments in which the control perfusion was the first solution used, the other $(n=12)$ featured a fatty acid solution before the control. There was no difference in water and solute absorption between the two groups. Water absorption was (mean $\pm \mathrm{SE}$ ) $1.3 \pm 0.4 \mathrm{ml} / \mathrm{min}$ in the first, and $1.3 \pm$ $0.2 \mathrm{ml} / \mathrm{min}$ in the latter group; xylose absorption was $24.4 \pm 5.9 \%$ and $23.0 \pm 3.5 \%$, respectively; and glucose absorption was $65.1 \pm 8.8 \%(n=6)$ and $72.9 \pm 6.7 \%(n=10)$. These data confirm the reversibility of the fatty acid effect under our experimental conditions.

The experiments reported here were not designed to establish a mechanism by which solute absorption is inhibited in the presence of fatty acids or dihydroxy bile acids; instead, they describe the phenomenon and document the broad range of solutes so affected. Solute movement across membranes is the net result of several driving forces including active transport processes, passive diffusion, and convection (Levitt et al., 1969). Our observations on active transport are limited; however, we did observe impaired 'uphill' transport of glucose in the presence of ricinoleate. A more precise study of active transport processes-for example, by the use of in vitro systems - may be difficult, as dihydroxy bile acids and ricinoleic acid are cytotoxic to many tissues in vitro (Gaginella et al., 1976). With regard to passive diffusion, it is clear that reduced intraluminal concentrations of glucose during fatty acid perfusion were not the cause for reduced solute transport, as the mean segment concentrations of glucose in the presence of fatty acids or bile acids were higher than during the perfusion with the control solutions (Table 2); moreover, in the presence of mannitol-induced fluid secretion, glucose and xylose absorption were unaffected (Table 2). However, we cannot quantify rates of diffusion under our experimental conditions.

Any hypothesis attempting to explain the effects of fatty acids and dihydroxy bile acids on intestinal 
transport will have to account not only for the changes in transport of electrolytes and water but also for those of organic solutes. Currently, three mechanisms are being proposed by which dihydroxy bile acids and fatty acids could alter intestinal water and electrolyte transport: (1) stimulation of adenylate cyclase (Conley et al., 1975a; Conley et al., 1975b; Binder, 1974; Binder et al., 1975), (2) alteration of intestinal permeability (Rummel et al., 1975), and (3) mucosal damage (Cline et al., 1976). Stimulation of adenylate cyclase might account for the secretion of electrolytes and water. However, as glucose absorption remains intact in the presence of water secretion induced by cholera toxin (Carpenter et al., 1968; Serebro et al., 1968), a process thought to be mediated by cyclic AMP (Field, 1971), this mechanism by itself is not a satisfactory explanation for the effects of fatty acids and dihydroxy bile acids on solute transport.

Bile acids and fatty acids can produce mucosal damage in the small intestine (Reynell and Spray, 1958; Dawson and Isselbacher, 1960; Teem and Phillips, 1972; Hajjar et al., 1975; Cline et al., 1976; Gaginella and Phillips, 1976). Indeed, inhibition of amino acid absorption by deoxycholate has been correlated with the degree of mucosal damage observed in perfused segments of rabbit jejunum (Hajjar et al., 1975). However, in the hamster jejunum perfused with dihydroxy bile acids, mucosal damage and fluid secretion could be in part dissociated (Teem and Phillips, 1972). Mucosal damage has been observed in animals fed cathartic doses of castor oil (Reynell and Spray, 1958), and Cline et al. (1976) and Gaginella and Phillips (1976) detected mucosal damage by scanning electron microscopy after perfusion of 8-10 mM ricinoleic acid in the hamster and rabbit small intestine, respectively. In our studies, we did not investigate the loss of mucosal integrity, but mucosal damage, if present, did not prevent recovery of normal water and sugar absorption within the 30-minute equilibration period.

Cline et al. (1976) observed that ricinoleic acid increased the plasma to lumen clearance of dextran (molecular weight 16000) and inulin in the hamster small intestine, and similar changes in inulin clearance are induced by ricinoleic acid in the rat colon (Bright-Asare and Binder, 1973). Dihydroxy bile acids also alter mucosal permeability in the rat small bowel and colon (Nell et al., 1975; Rummel et al., 1975). In our experiments, reduced net solute absorption, however, does not appear to be caused by increased diffusion of solutes from plasma to lumen. Recovery of glucose during perfusion with $2 \mathrm{mM}$ glucose, in the presence of $10 \mathrm{mM}$ ricinoleic acid, a condition which would favour diffusion into the lumen, did not exceed the input into the test segment.
Also, no glucose was found during perfusion of a glucose-free solution containing $7 \mathrm{mM}$ oleic or $5 \mathrm{mM}$ glycodeoxycholic acid (Brown and Ammon, unpublished observation). Moreover, no amino acids other than those infused were detected in the effluents collected in experiment no. 4. Finally, the absorption of folic acid and mono-olein was calculated isotopically and the results indicate a decrease in lumen to plasma transport of these compounds.

Several less likely mechanisms should be considered to explain the observations. Conditions within the intestinal lumen might be altered by the physical effects of fluid secretion-for example, net movement of fluid from the mucosal surface into the bulk phase could alter the dimensions of the unstirred water layer (Dietschy et al., 1971). In this event, fluid secretion induced by mannitol or cholera toxin (Carpenter et al., 1968; Serebro et al., 1968) shouldalso influence solute movements but it does not. Dihydroxy bile acids (Dietschy, 1967) and fatty acids (Taketa and Pogell, 1966) also interfere with intracellular enzymatic reactions in vitro. However, we feel the inhibition of solute transport observed is too general a phenomenon to be explained solely by defects in the intermediary metabolism.

Our findings might pertain to certain clinical circumstances. The fatty acid concentrations used in our experiments are well within the range of postprandial concentrations of fatty acids observed in the upper jejunum (Hofmann and Borgström, 1964; Porter and Saunders, 1971). Normally, fatty acids are rapidly absorbed and any influence on water and electrolyte transport will be limited to a short segment of proximal intestine. In addition, other so far unidentified constituents of the postprandial intestinal contents could modify the effects of fatty acids. However, $2.5 \mathrm{mM}$ lecithin, which completely blocked the effects of $5 \mathrm{mM}$ glycodeoxycholic acid (Wingate et al., 1973b), did not alter the effects of $5 \mathrm{mM}$ ricinoleic acid on water and glucose transport. The slight improvement in xylose absorption did not reach statistical significance. On the other hand, when impaired fat absorption leads to steatorrhoea, retention of fatty acids in the lumen might be expected to reduce solute absorption over the greater length of intestine and may possibly lead to malabsorption of other nutrients as well.

The authors are grateful to Ms Anne Haddad, $\mathrm{Mr}$ Rodney J. Sandberg, Ms Monica Wnuk, and Ms Louise Luedtke for their expert technical assistance. This investigation was supported in part by research grants AM 6908, AM 17941-01, and training grant TIAM 5259 from the National Institutes of Health, United States Public Health Service. It was also sup- 
ported by the Medical Research Service of the Veterans Administration.

\section{References}

Alvarado, F. (1966). D-xylose active transport in the hamster small intestine. Biochimica et Biophysica Acta, 112, 292306.

Ammon, H. V., and Phillips, S. F. (1974). Inhibition of ileal water absorption by intraluminal fatty acids. Influence of chain length, hydroxylation and conjugation of fatty acids. Journal of Clinical Investigation, 53, 205-210.

Ammon, H. V., Thomas, P. J., and Phillips, S. F. (1974). Effects of oleic and ricinoleic acids on net jejunal water and electrolyte movement. Perfusion studies in man. Journal of Clinical Investigation, 53, 374-379.

Binder, H. J. (1974). Cyclic adenosine monophosphate controls bile salt and hydroxy fatty acid-induced colonic electrolyte secretion. Journal of Clinical Investigation, 53, 7a-8a. (Abstract.)

Binder, H. J., Filburn, C., and Volpe, B. T. (1975). Bile salt alteration of colonic electrolyte transport: role of cyclic adenosine monophosphate. Gastroenterology, 68, 503-508.

Bright-Asare, P., and Binder, H. J. (1973). Stimulation of colonic secretion of water and electrolytes by hydroxy fatty acids. Gastroenterology, 64, 81-88.

Burke, V., Gracey, M., Thomas, J., and Malajczuk, A. (1975). Inhibition of intestinal amino acid absorption by unconjugated bile salt in vivo. Australian and New Zealand Journal of Medicine, 5, 430-432.

Carpenter, C. C. J., Sack, R. B., Feeley, J. C., and Steenberg, R. W. (1968). Site and characteristics of electrolyte loss and effect of intraluminal glucose in experimental canine cholera. Journal of Clinical Investigation, 47, 1210-1220.

Cline, W. S., Lorenzsonn, V., Benz, L., Bass, P., and Olsen, W. A. (1976). The effects of sodium ricinoleate on small intestinal function and structure. Journal of Clinical Investigation, 58, 380-390.

Conley, D. R., Bonorris, G. G., Coyne, M. J., Chung, A., and Schoenfield, L. J. (1975a). Effect of bile acids and fatty acids on adenylate cyclase activity in human colonic mucosa. Clinical Rescarch, 23, 518A. (Abstract.)

Conley, D. R., Coyne, M. J., Chung, A., Bonorris, G. G., and Schoenfield, L. J. (1975b). Mechanism of bile acid diarrhea: the role of cyclic AMP in colonic secretion. Gastroenterology, 68, 877. (Abstract.)

Dawson, A. M., and Isselbacher, K. J. (1960). Studies on lipid metabolism in the small intestine with observations on the role of bile salts. Journal of Clinical Investigation, 39, 730-740.

Dietschy, J. M. (1967). Effects of bile salts on intermediate metabolism of the intestinal mucosa. Federation Proceedings, 26, 1589-1598.

Dietschy, J. M., Sallee, V. L., and Wilson, F. A. (1971). Unstirred water layers and absorption across the intestinal mucosa. Gastroenterology, 61, 932-934.

Field, M. (1971). Intestinal secretion: effect of cyclic AMP and its role in cholera. New England Journal of Medicine, 284, 1137-1144.

Forth, W., Rummel, W., and Glasner, H. (1966). Zur resorptionshemmenden Wirkung von Gallensäuren. NaunynSchmiedeberg's Archiv für Experimentelle Pathologie und Pharmakologie, 254, 364-380.

Gaginella, T. S., Haddad, A. C., Go, V. L. W., and Phillips, S. F. (1976). Cytotoxic action of ricinoleic acid and other surfactants on isolated intestinal epithelial cells. Federation Proceedings, 35, 764. (Abstract.)

Gaginella, T. S., and Phillips, S. F. (1976). Ricinoleic acid (castor oil) alters intestinal surface structure. A scanning electronmicroscopic study. Mayo Clinic Proceedings, 51, 6-12.

Goodwin, J. F. (1970). Method for simultaneous direct estimation of glucose and xylose in serum. Clinical Chemistry, 16, 85-91.

Hajjar, J. J., Khuri, R. N., and Bikhazi, A. B. (1975). Effect of bile salts on amino acid transport by rabbit intestine. American Journal of Physiology, 229, 518-523.

Hofmann, A. F. (1963). The function of bile salts in fat absorption. The solvent properties of dilute micellar solutions of conjugated bile salts. Biochemical Journal, 89, $57-$ 68.

Hofmann, A. F., and Borgström, B. (1964). The intraluminal phase of fat digestion in man: the lipid content of the micellar and oil phases of intestinal content obtained during fat digestion and absorption. Journal of Clinical Investigation, 43, 247-257.

Kameda, H., Abei, T., Nasrallah, S., and Iber, F. L. (1968). Functional and histological injury to intestinal mucosa produced by hypertonicity. American Journal of Physiology, 214, 1090-1095.

Krag, E., and Phillips, S. F. (1974). Active and passive bile acid absorption in man: perfusion studies of the ileum and jejunum. Journal of Clinical Investigation, 53, 1686-1694.

Larsen, P. R., Ross, J. E., and Tapley, D. F. (1964). Transport of neutral, dibasic and $\mathrm{N}$-methyl-substituted amino acids by rat intestine. Biochimica et Biophysica Acta, 88, 570-577.

Lenormand, Y., Rautureau, M., Mary, J. Y., and Rambaud, J. C. (1975). Absorption intestinale de la vitamine $D_{3}$, de l'acide linoléique et du cholestérol à partir de solutions micellaires: étude chez l'homme normal par la méthode de perfusion 'in situ'. Biologie et Gastro-enterologie (Paris), 8, 207-221.

Levitt, D. G., Hakim, A. A., and Lifson, N. (1969). Evaluation of components of transport of sugars by dog jejunum in vivo. American Journal of Physiology, 217, 777-783.

Matuchansky, C., and Bernier, J-J. (1973). Effect of prostaglandin $\mathrm{E}_{1}$ on glucose, water and electrolyte absorption in the human jejunum. Gastroenterology, 64, 1111-1118.

Nasrallah, S. M., Coburn, W. M., Jr, and Iber, F. L. (1968). The effect of hypertonic mannitol on the intestine of man. Johns Hopkins Medical Journal, 123, 134-137.

Nell, G., Forth, W., Freiberger, T., Rummel, W., and Wanitschke, R. (1975). Characterization of permeability changes by test molecules in rat colonic mucosa under the influence of sodium deoxycholate. In Advances in Bile Acid Research, pp. 419-424. Edited by S. Matern, J. Hackenschmidt, P. Bach, and W. Gerok. Schattauer: New York.

Okita, G. T., Kabara, J. J., Richardson, F., and LeRoy, G. V. (1957). Assaying compounds containing $\mathrm{H}^{3}$ and $\mathrm{C}^{14}$. Nucleonics, 15 (6), 111-114.

Porter, H. P., and Saunders, D. R. (1971). Isolation of the aqueous phase of human intestinal contents during the digestion of a fatty meal. Gastroenterology, 60, 997-1007.

Reynell, P. C., and Spray, G. H. (1958). Chemical gastroenteritis in the rat. Gastroenterology, 34, 867-873.

Riddell, W. M., and Jordan, P. H. (1966). Enhancement of glucose absorption by oleic acid. Proceedings of the Society for Experimental Biology and Medicine, 122, 1204-1208.

Rummel, W., Nell, G., and Wanitschke, R. (1975). Action mechanisms of antiabsorptive and hydragogue drugs. In Intestinal Absorption and Malabsorption, pp. 209-227. Edited by T. Z. Csaky. Raven Press: New York.

Russell, R. I., Allan, J. G., Gerskowitch, V. P., and Cochran, K. M. (1973). The effect of conjugated and unconjugated bile acids on water and electrolyte absorption in the human jejunum. Clinical Science and Molecular Medicine, 45, 301311.

Serebro, H. A., Bayless, T. M., Hendrix, T. R., Iber, F. L., and McGonagle, T. (1968). Absorption of D-glucose by the 
rabbit jejunum during cholera toxin-induced diarrhoea. Nature, 217, 1272-1273.

Sladen, G. E., and Harries, J. T. (1972). Studies on the effects of unconjugated dihydroxy bile salts on rat small intestinal function in vivo. Biochimica et Biophysica Acta, 288, 443-456.

Taketa, K., and Pogell, B. M. (1966). The effect of palmityl coenzyme A on glucose 6-phosphate dehydrogenase and other enzymes. Journal of Biological Chemistry, 241, 720726.

Teem, M. V., and Phillips, S. F. (1972). Perfusion of the hamster jejunum with conjugated and unconjugated bile acids: inhibition of water absorption and effects on morphology. Gastroenterology, 62, 261-267.

Wanitschke, R., and Ammon, H. V. (1976). Deoxycholic acid inhibits the absorption of fatty acids in the human jejunum. Gastroenterologv 70, 859. (Abstract.)

Wingate, D. L., Krag, E., Mekhjian, H. S., and Phillips, S. F. (1973a). Relationships between ion and water movement in the human jejunum, ileum and colon during perfusion with bile acids. Clinical Science and Molecular Medicine, 45, 593 606.

Wingate, D. L., Phillips, S. F., and Hofmann, A. F. (1973b). Effect of glycine-conjugated bile acids with and without lecithin on water and glucose absorption in perfused human jejunum. Journal of Clinical Investigation, 52, 1230-1236.

Wingate, D. L., Sandberg, R. J., and Phillips, S. F. (1972). A comparison of stable and ${ }^{14} \mathrm{C}$-labelled polyethylene glycol as volume indicators in the human jejunum. Gut, 13, 812815. 